\title{
Recurrence of renal cell carcinoma diagnosed using contralateral adrenal biopsy with endoscopic ultrasound-guided fine-needle aspiration
}

\author{
AZUSA TANIMOTO $^{1}$, SHINII TAKEUCHI $^{1}$, HIROSHI YAEGASHI ${ }^{2}$, HIROSHI KOTANI $^{1}$, \\ HIDENORI KITAI $^{1}$, SHIGEKI NANJO ${ }^{1}$, HIROMICHI EBI ${ }^{1}$, KANAME YAMASHITA ${ }^{1}$, \\ HISATSUGU MOURI $^{1}$, KOUSHIRO OHTSUBO ${ }^{1}$, HIROKO IKEDA $^{3}$ and SEIJI YANO ${ }^{1}$ \\ ${ }^{1}$ Division of Medical Oncology, Cancer Research Institute, Kanazawa University, Kanazawa, Ishikawa 920-0934; \\ ${ }^{2}$ Department of Integrative Cancer Therapy and Urology, Kanazawa University Graduate School of Medical Science; \\ ${ }^{3}$ Division of Pathology, Kanazawa University Hospital, Kanazawa, Ishikawa 920-8641, Japan
}

Received May 20, 2015; Accepted October 21, 2016

DOI: $10.3892 / \mathrm{mco} .2016 .739$

\begin{abstract}
A 76-year-old female in whom a renal cell carcinoma (RCC) lesion was resected 19 years previously presented to our hospital with cognitive dysfunction. Magnetic resonance imaging and computed tomography revealed nodules in the brain, lung, adrenal gland and a pelvic osteolytic lesion. To identify the primary cancer site, the present study performed endoscopic ultrasound-guided fine-needle aspiration (EUS-FNA) of the left adrenal lesion. Consequently, the pathological findings of the tissue obtained by EUS-FNA were similar to those of the previous nephrectomy specimen, revealing that the adrenal lesion was the recurrence of RCC. The majority of the metastatic lesions in the patient were reduced in size by the multiple kinase inhibitor, pazopanib. Contralateral adrenal metastasis of RCC is rare and the use of EUS-FNA in the diagnosis of adrenal lesions remains to be elucidated. This is a rare case of adrenal lesion, diagnosed by EUS-FNA. Therefore, EUS-FNA is considered to be a useful diagnostic modality of adrenal metastases from unidentified primary tumor types.
\end{abstract}

\section{Introduction}

Renal cell carcinoma (RCC), which accounts for $\sim 5 \%$ of all epithelial cancer types, is the ninth most common cancer worldwide. Around $20 \%$ of patients experience recurrence or

Correspondence to: Dr Azusa Tanimoto, Division of Medical Oncology, Cancer Research Institute, Kanazawa University, 13-1 Takara-Machi, Kanazawa, Ishikawa 920-0934, Japan

E-mail: atanimoto@staff.kanazawa-u.ac.jp

Key words: renal cell carcinoma, contralateral adrenal metastasis, late recurrence, endoscopic ultrasound-guided fine-needle aspiration, pazopanib develop metastatic RCC following nephrectomy (1). Although late recurrence of RCC following curative initial surgery is not a rare event, a previous study demonstrated that contralateral adrenal metastasis of RCC is rare (2). Endoscopic ultrasound-guided fine-needle aspiration (EUS-FNA) is a relatively novel modality for obtaining samples from deep-seated lesions. In a previous study, adrenal gland samples obtained by EUS-FNA biopsy were adequate for determining a pathological diagnosis (3). The present study reported a rare case of contralateral adrenal metastasis of RCC, which was diagnosed by EUS-FNA.

\section{Case report}

A 76-year-old female with a complaint of cognitive dysfunction visited the Department of Neurosurgery, Kanazawa University Hospital (Ishikawa, Japan). The patient was previously diagnosed with RCC of the right kidney in the Department of Urology, Public Central Hospital of Matto (Ishikawa, Japan) 19 years previously. The right kidney was removed and the patient received no adjuvant therapy at that time. A physical examination revealed no findings other than disorientation, and laboratory data, including tumor markers, revealed no notable findings. Brain gadolinium contrast-enhanced magnetic resonance imaging uncovered several nodules (Fig. 1), whereas chest and abdominal computed tomography (CT) identified a single nodule in the right lower lobe of the lungs, a mass in the left adrenal gland and an osteolytic lesion in the left pelvis (Data not shown). On the basis of these findings, the patient was diagnosed with a metastatic brain tumor. Following diagnosis, the patient received stereotactic radiosurgery with gamma knife therapy for the brain lesions. To identify the primary lesion, the present case study attempted to obtain histological confirmation of the adrenal lesion using EUS-FNA, available in the department. FNA was performed via the transgastric approach with linear EUS (GF-UCT260; Olympus, Tokyo, Japan), and two passes were made with a 19-gauge needle (Sono Tip Pro Control; Medi-Globe, Rosenheim, Germany). EUS revealed a homogeneous hypoechoic mass with a 


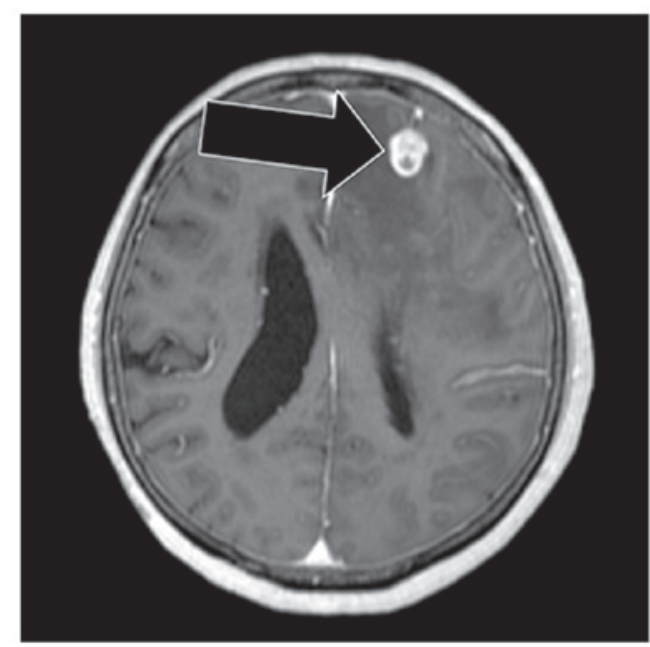

Figure 1. Magnetic resonance imaging of the brain revealed a well-enhanced nodule (arrow), accompanied by brain swelling.

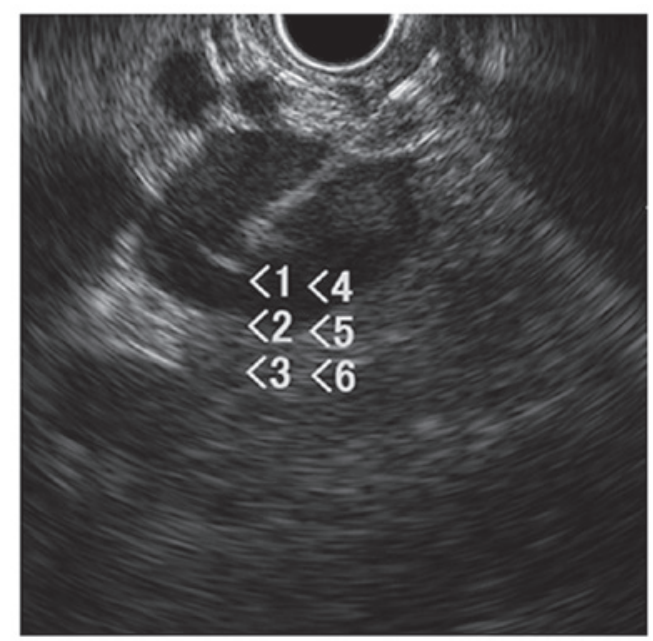

Figure 2. Endoscopic ultrasonography revealed a homogeneous hypoechoic mass $\left(26 \times 20 \mathrm{~mm}^{2}\right)$ in the left adrenal gland. Numbers refer to biopsy sample.

maximum diameter of $26 \mathrm{~mm}$ within the left adrenal gland (Fig. 2). Tissue obtained from the aspirated material revealed clear cytoplasmic and vascular stroma (Fig. 3A), and these findings were similar to those of the nephrectomy specimen obtained 19 years previously (Fig. 3B). Histologically, a definitive diagnosis of metastatic RCC was made. Based on the diagnosis, the patient received targeted therapy with pazopanib (Votrient ${ }^{\circledR}$; GlaxoSmithKline, Middlesex, UK; $800 \mathrm{mg}$ orally, once/day). The majority of the metastatic lesions of RCC regressed following 1 month of treatment (Fig. 4A-C).

\section{Discussion}

RCC, accounting for $2-3 \%$ of all cancer types, is the most common cause of mortality concerning urologic malignancies (4), and it is more common in males compared with females. RCC generally occurs between 50 and 70 years of age, however, it can occur at any age. Risk factors for RCC are family history, including von Hippel-Lindau (VHL) disease and Birt-Hogg-Dubé syndrome, cigarette smoking, obesity,
A

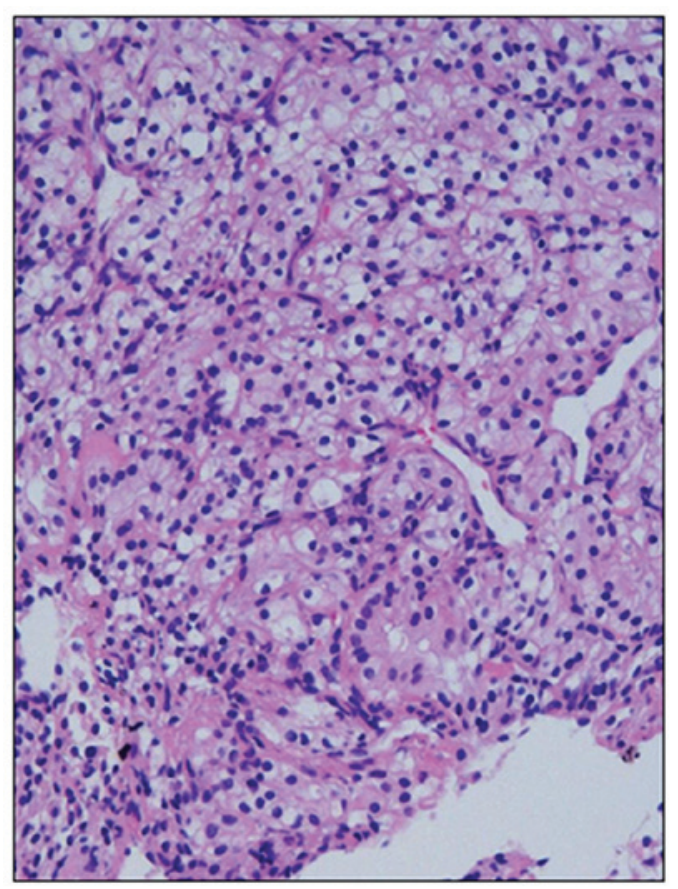

$\mathbf{B}$

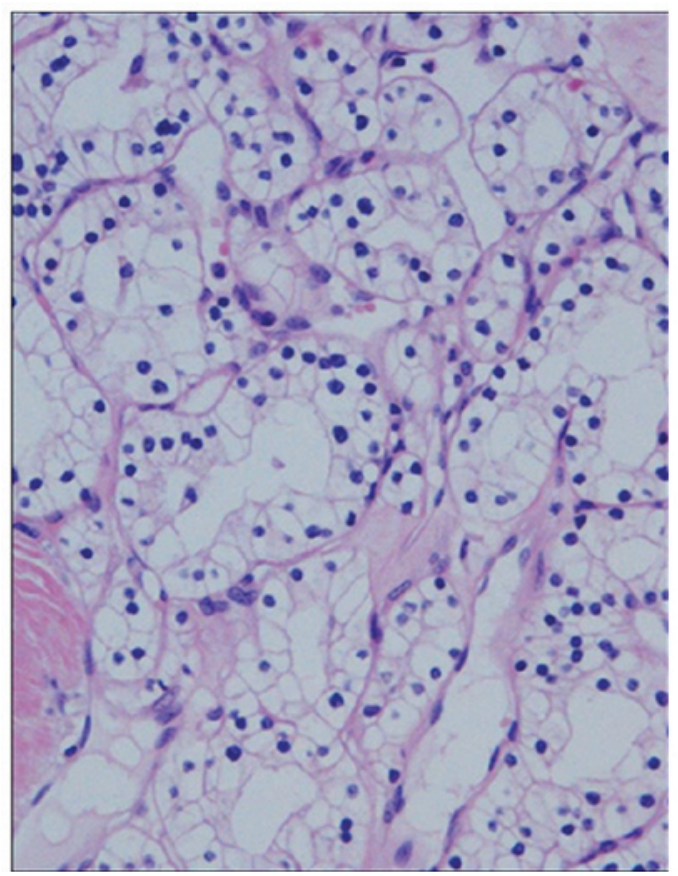

Figure 3. Histological staining of specimens from the left adrenal gland. (A) A photomicrograph of hematoxylin and eosin staining of endoscopic ultrasound-guided fine-needle aspiration specimen from the left adrenal gland revealed clear cells with an abundant cytoplasm and rich vascular stroma metastatic renal cell carcinoma (magnification, x100). (B) A photomicrograph of the hematoxylin and eosin stained resected specimen revealed the identical findings as in the previous specimen (magnification, x200).

and hypertension. Concerning family history, an inherited predisposition to RCC accounts for only 3-4\% of all cases. By contrast, the majority of RCCs occur sporadically (5). Histologically, RCC is classified on the basis of the tissue type. In particular, clear cell RCC accounts for $\sim 80 \%$ of all RCCs, whereas papillary $(<15 \%)$, chromophobe $(<5 \%)$ and collecting duct carcinomas $(<1 \%)$ comprise the remaining cases. Several previous studies confirmed that $30-60 \%$ of sporadic clear cell 
A

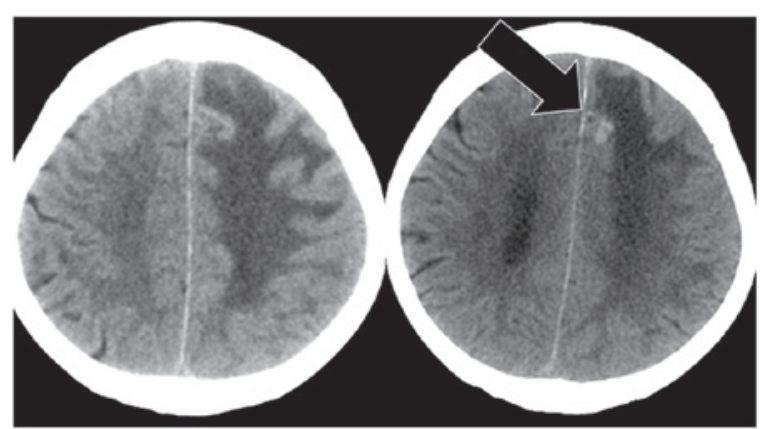

B

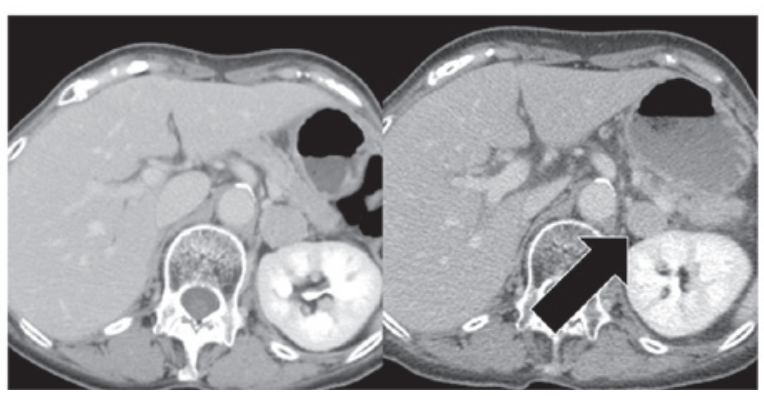

C

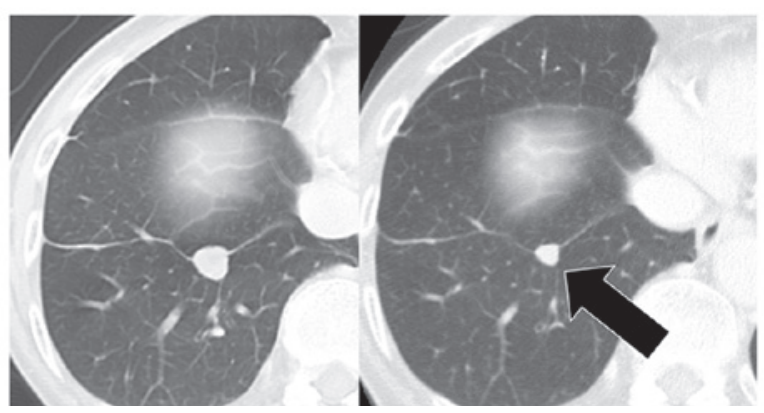

Figure 4. (A) CT imaging revealed a nodule with surrounding edema in the left parietal lobe prior to treatment (left). The size of the nodule (arrow) and edema reduced following treatment (right). (B) CT imaging revealed a mass in the left adrenal gland (left). The size of the mass (arrow) reduced following treatment (right). (C) CT imaging revealed a nodule in the right lower lobe prior to treatment (left). The size of the nodule (arrow) reduced following treatment (right panel). CT, computed tomography.

RCCs express mutations in $V H L$, which consequently leads to high expression of vascular endothelial growth factor (VEGF), transforming growth factor $\alpha$, glucose transporter-1 and carbonic anhydrase 9 , associated with arborizing vasculature and abundant cytoplasm $(6,7)$. It was determined that $~ 75 \%$ of patients with RCC are diagnosed with localized disease, and surgical resection has been the gold standard for treating localized RCC. In addition, it is evident from two previous randomized phase III studies that cytoreductive nephrectomy prior to systemic treatment improves the survival rate for patients with metastatic RCC $(8,9)$. By contrast, systemic treatment of metastatic RCC has markedly changed over the last decade as a result of the development of targeted therapies and immunotherapies (1).

Although $\sim 60 \%$ of cases of recurrent RCC following nephrectomy for localized disease occur within 12 months, late recurrence of RCC beyond 10 years, as noted in the present study, is unusual. According to a previous study performed by Nakano et al (10) and Miyao et al (11), 5\% of patients who were disease-free for 10 years following nephrectomy devel- oped late recurrence of RCC. Furthermore, Miyao et al (11) noted that lymph node metastasis was predictive of late recurrence. Conversely, lymph node metastasis was not observed in the present patient at the initial surgery.

Metastasis of RCC can occur at any organ, including the lungs, kidneys, bone, brain, liver and adrenal gland. The contralateral adrenal grand, which was biopsied in the patient, was a rare site of metastasis of RCC, being detected in $2.5 \%$ of patients with metastatic RCC at autopsy (2). The spread of RCC to the contralateral adrenal gland in the present case may not have been a recent event since a previous study by Lau et al (12) reported that the mean interval to developing contralateral adrenal metastasis following radical nephrectomy is 5.2 years (12).

EUS-FNA was developed in 1992 and has been widely used for diagnosing perigastrointestinal lesions. The diagnostic capacity of EUS-FNA for adrenal lesions has been less investigated in comparison with that of pancreatic lesions, for which the sensitivity and specificity were reported as $78-95$ and $75-100 \%$, respectively (13). A transgastric approach of EUS-FNA can provide proximity to the left adrenal gland compared with traditional percutaneous techniques, including CT-guided FNA, significantly reducing the risk of complications (14). Additionally, real-time ultrasound-guided needling with color Doppler guidance enables the avoidance of vascular structures, and therefore, EUS-FNA decreases the risk of bleeding. Considering the advantages of EUS-FNA, the modality is applicable for diagnosing adrenal metastases of unknown primary tumors, as observed in the present case. However, FNA biopsy of adrenal pheochromocytoma can induce fatal hypertensive crisis. Therefore, EUS-FNA of adrenal lesions is best performed if the possibility of pheochromocytoma has been eliminated. Regarding the patient, the success in obtaining adrenal gland tissue using EUS-FNA prevented unnecessary diagnostic surgeries.

Targeted therapies, including targeting the VEGF receptor and the mechanistic targeting of rapamycin inhibitors, for metastatic RCC have been previously developed (1). With this development, progression-free survival (PFS) for patients with metastatic RCC has been markedly prolonged. The first-line treatment for the present patient was pazopanib, which proved to be non-inferior to sunitinib with respect to PFS. Pazopanib was selected as the treatment modality, as a result of its superior safety and quality-of-life profiles compared with sunitinib (15). It was determined that pazopanib is an appropriate treatment modality for patients with metastatic RCC who have mild cognitive impairment, including the present patient, as these patients may have difficulty informing caregivers about adverse events.

Progress in the diagnosis of rare cases of contralateral adrenal metastasis from RCC indicates that EUS-FNA of adrenal metastases of unknown primary origin is available and beneficial from the perspective of invasiveness.

\section{References}

1. Jonasch E, Gao J and Rathmell WK: Renal cell carcinoma. BMJ 349: g4797, 2014.

2. Saitoh H, Nakayama M, Nakamura K and Satoh T: Distant metastasis of renal adenocarcinoma in nephrectomized cases. J Urol 127: 1092-1095, 1982. 
3. Jhala NC, Jhala D, Eloubeidi MA, Chhieng DC, Crowe DR, Roberson J and Eltoum I: Endoscopic ultrasound-guided fine-needle aspiration biopsy of the adrenal glands: Analysis of 24 patients. Cancer 102: 308-314, 2004.

4. Chin AI, Lam JS, Figlin RA and Belldegrun AS: Surveillance strategies for renal cell carcinoma patients following nephrectomy. Rev Urol 8: 1-7, 2006.

5. Lipworth L, Tarone RE, Lund L and McLaughlin JK: Epidemiologic characteristics and risk factors for renal cell cancer. Clin Epidemiol 1: 33-43, 2009.

6. Shiao YH, Forsti A, Egevad L, Anderson LM, Lindblad P and Hemminki K: VHL down-regulation and differential localization as mechanisms in tumorigenesis. Kidney Int 64 1671-1674, 2003.

7. Gnarra JR, Tory K, Weng Y, Schmidt L, Wei MH, Li H, Latif F, Liu S, Chen F, Duh FM, et al: Mutations of the VHL tumour suppressor gene in renal carcinoma. Nat Genet 7: 85-90, 1994

8. Mickisch GH, Garin A, van Poppel H, de Prijck L and Sylvester R; European Organisation for Research and Treatment of Cancer (EORTC) Genitourinary Group: Radical nephrectomy plus interferon-alfa-based immunotherapy compared with interferon alfa alone in metastatic renal-cell carcinoma: A randomised trial. Lancet 358 966-970, 2001.
9. Flanigan RC, Salmon SE, Blumenstein BA, Bearman SI, Roy V, McGrath PC, Caton JR Jr, Munshi N and Crawford ED: Nephrectomy followed by interferon alfa-2b compared with interferon alfa-2b alone for metastatic renal-cell cancer. N Engl J Med 345: 1655-1659, 2001.

10. Nakano E, Fujioka H, Matsuda M, Osafune M, Takaha M and Sonoda T: Late recurrence of renal cell carcinoma after nephrectomy. Eur Urol 10: 347-349, 1984.

11. Miyao N, Naito S, Ozono S, Shinohara N, Masumori N, Igarashi T, Nakao M, Tsushima T, Senga Y, Horie S, et al: Late recurrence of renal cell carcinoma: Retrospective and collaborative study of the Japanese society of renal cancer. Urology 77: 379-384, 2011.

12. Lau WK, Zincke H, Lohse CM, Cheville JC, Weaver AL and Blute ML: Contralateral adrenal metastasis of renal cell carcinoma: Treatment, outcome and a review. BJU Int 91: 775-779, 2003.

13. Yoshinaga S, Suzuki H, Oda I and Saito Y: Role of endoscopic ultrasound-guided fine needle aspiration (EUS-FNA) for diagnosis of solid pancreatic masses. Dig Endosc 23 (Suppl 1): S29-S33, 2011.

14. Ang TL, Chua TS, Fock KM, Tee AK, Teo EK and Mancer K: EUS-FNA of the left adrenal gland is safe and useful. Ann Acad Med Singapore 36: 954-957, 2007.

15. Motzer RJ, Hutson TE, Cella D, Reeves J, Hawkins R, Guo J, Nathan P, Staehler M, de Souza P, Merchan JR, et al: Pazopanib versus sunitinib in metastatic renal-cell carcinoma. N Engl J Med 369: 722-731, 2013. 